\title{
Lack of Synergy Between $\beta$-Agonist Treatment and a Blockage of Sarcoplasmic Calcium Flow in a Rat Cancer Cachexia Model
}

This article was published in the following Dove Press journal: OncoTargets and Therapy

\author{
Silvia Busquets ${ }^{1,2}$ \\ Marta Castillejo' \\ Queralt Jovél \\ Baptiste Jude ${ }^{3}$ \\ Patricia Mejías' \\ Francisco J López- \\ Soriano ${ }^{1,2}$ \\ Josep M Argilés ${ }^{1,2}$
}

'Cancer Research Group, Departament de Bioquímica i Biomedicina Molecular,

Facultat de Biologia, Universitat de

Barcelona, Barcelona, Spain; ${ }^{2}$ Institut de Biomedicina de la Universitat de

Barcelona, Barcelona, Spain; ${ }^{3}$ Laboratoire de Physiologie - EA 4324 ORPHY, IBSAM,

Université de Bretagne Occidentale,

Brest, France
Correspondence: Silvia Busquets

Cancer Research Group, Departament de Bioquímica i Biomedicina Molecular, Facultat de Biologia, Universitat de Barcelona, Diagonal 643, Barcelona, 08028, Spain

Tel +34-934021002

Fax +34-934021559

Email silviabusquets@ub.edu
Background: During cancer cachexia, both skeletal muscle and adipose tissue losses take place. The use of $\beta 2$-agonists, formoterol in particular, has proven to be very successful in the treatment of the syndrome in pre-clinical models. The object of the present research was to study the effects of a combination of formoterol and dantrolene, an inhibitor of the ryanodine receptor 1 (RyR1), on body weight loss and cachexia in tumour-bearing animals. Methods: Rats were separated into two groups: controls (C) and tumour bearing (TB). TB group was further subdivided into four groups: untreated (saline as a vehicle), treated with Formoterol (TF) $(0,3 \mathrm{mg} / \mathrm{kg}$ body weight in saline, subcutaneous (s.c.), daily), treated with Dantrolene (TD) $(5 \mathrm{mg} / \mathrm{kg}$ body weight in saline, subcutaneous (s.c.), daily), and doubletreated treated (TFD) with Formoterol $(0,3 \mathrm{mg} / \mathrm{kg}$ body weight, subcutaneous (s.c.), daily) and Dantrolene ( $5 \mathrm{mg} / \mathrm{kg}$ body weight, subcutaneous (s.c.), daily). 7 days after tumour transplantation, muscle weight, grip force, and total physical activity were specified in all experimental groups.

Results: While formoterol had, as in previous studies, a very positive effect in reducing muscle weight loss, dantrolene had no effects, neither on skeletal muscle nor on any of the parameters studied. Finally, the combined treatment (formoterol and dantrolene) did not result in any significant benefit on the action of the $\beta 2$-agonist.

Conclusion: It is concluded that, in the preclinical cachectic model used, no synergy exists between $\beta 2$-agonist treatment and the blockade of sarcoplasmic-calcium flow.

Keywords: cancer cachexia, skeletal muscle, dantrolene, formoterol, calcium, ryanodine receptor 1

\section{Background}

The percentage of cancer patients affected by cachexia varies from 50 to $80 \%$ constituting a useful survival estimate. Cachexia is responsible for more than $20 \%$ of cancer deaths in humans. ${ }^{1}$ Moreover, cachexia is linked with a decrease in physical activity ${ }^{2}$ and results in a poor quality of life and a decreased efficacy and outcome of antitumoural treatment. ${ }^{3,4}$ In 2008 a consensus, ${ }^{5}$ defined cachexia as a

complex metabolic syndrome associated with underlying illness and characterised by loss of muscle with or without loss of fat mass. The prominent clinical feature of cachexia is weight loss. Anorexia, inflammation, insulin resistance and increased muscle protein breakdown are frequently associated with cachexia. ${ }^{5}$ 
Loss of both adipose tissue and skeletal muscle are important but the loss of skeletal muscle is the most important factor in the outcome of cachexia since it influences survival together with muscle force and functioning, essential in the recovery of the patient. ${ }^{6}$

The treatment of cancer cachexia includes many approaches and strategies but, unfortunately, they cannot completely abolish weight loss. Those approaches concentrate, basically, in either fighting anorexia and normalizing metabolic alterations or both. ${ }^{7,8}$ Concerning the latter, $\beta 2$-agonists, formoterol, in particular, have important anticachectic effects. ${ }^{9}$ The action of formoterol is based on the prevention of muscle wasting by inhibiting proteolysis (decreasing the activation of the ubiquitin-dependent proteolytic system, main mechanism activated in muscle wasting conditions) and apoptosis in muscle tissue. ${ }^{9,10}$ The anti-cachectic effects of the drug affect both physical activity and grip force, thus improving physical performance in cachectic tumour-bearing animals. ${ }^{11}$ In humans, the combination of formoterol and the orexigenic drug megestrol acetate also resulted in a promising therapy in cancer cachexia. ${ }^{12}$

It is well known that mitochondria and sarcoplasmic reticulum (SR) play a key role in muscular function. Calcium released from SR, stimulates mitochondrial ATP production helping to meet increased energy demand during muscle contraction (process called excitation-contraction coupling). ${ }^{13}$ Moreover, functionally intact mitochondria inhibit undesired localized SR calcium release by controlling the local redox environment of the calcium release units in normal cases. ${ }^{13}$ Thus, bidirectional SR-mitochondrial communication provides a powerful local control mechanism for integrating calcium release/reuptake and ATP utilization during muscle contraction with ATP production and skeletal muscle bioenergetics. ${ }^{14}$ In the case of cachexia, an uncontrolled release of calcium ions from the SR, due to the oxidation of ryanodine receptor 1 (RyR1), contributes to muscle weakness. ${ }^{15}$ In addition, the utilization of S107, which prevent RyR1 dysfunction by increasing the link with it endogenous regulator calpastatin, protects muscle weakness acquired during cancer cachexia (breast cancer cells DA-MB-231), with recovery of the contraction force, but has no beneficial effect on muscle wasting. ${ }^{15}$ On the other hand, dantrolene, an inhibitor of the RyR1, is able to suppress the calcium overload release from the $\mathrm{SR},{ }^{16}$ but its use in animals bearing the AH-130 Yoshida ascites hepatoma -a highly cachectic tumour- failed to prevent muscle wasting and had no effects on the skeletal muscle protein degradation rate. ${ }^{17}$ The aim of the present investigation was to explore if the combination of formoterol and dantrolene had any synergistic effect on cancer-related cachexia.

\section{Methods}

\section{Animals}

Male Wistar rats (6 weeks-old) (Harlan, Barcelona, Spain) were kept in individual cages at a constant temperature of $22 \pm 2{ }^{\circ} \mathrm{C}$ with a regular light-dark cycle (light from 08:00 a.m. to 08:00 p.m.) and access to food and water (free). Intraperitoneal injection of $10^{8} \mathrm{AH}-130$ Yoshida ascites hepatoma cells obtained from exponential tumours resulted in experimental cachexia as previously described $^{18}$ Food intake was measured every day. The protocol was approved by the Bioethical Committee of the University of Barcelona In addition, all animal handling was made following the European Community guidelines for the use of experimental animals. ${ }^{19}$

\section{Experimental Design}

Animals were randomized and divided into two groups, the so-called controls (C) and tumour bearing (TB). TB group was further subdivided into four subgroups: untreated (saline as a vehicle), treated with Formoterol (TF) $(0,3 \mathrm{mg} / \mathrm{kg}$ body weight in saline, subcutaneous (s. c.), daily), treated with Dantrolene (TD) (5 $\mathrm{mg} / \mathrm{kg}$ body weight in saline, subcutaneous (s.c.), daily), and doubletreated treated (TFD) with Formoterol $(0,3 \mathrm{mg} / \mathrm{kg}$ body weight, subcutaneous (s.c.), daily) and Dantrolene ( $5 \mathrm{mg} / \mathrm{kg}$ body weight, subcutaneous (s.c.), daily). 7 days following tumour inoculation, animals were weighed and anesthetized with an intraperitoneal (i.p.) injection of ketamine/xylazine mixture (3:1) (Imalgene $^{\circledR}$ and Rompun ${ }^{\circledR}$ respectively). Animals were euthanized by performing an incision in the aorta. Tumour volume was determined on the day of sacrifice. Tissues samples were rapidly extracted, weighed, and frozen using liquid nitrogen.

\section{Biochemicals}

Formoterol was kindly given by Industriale Chimica s.r.l. (Saronno, Italy), Dantrolene was purchased from Abcam Co. (Cambridge, England). 


\section{Total Physical Activity}

During the last 24 hours prior to the sacrifice, total physical activity (TPA) (IR ACTIMETER System and ACTITRAK software from Panlab, Barcelona) was measured in the different experimental groups, using activity sensors that convert individual changes in the infrared pattern -caused by movements of the animals- into arbitrary activity counts. ${ }^{20}$ The animals remained in their individual cages while performing the measurements. In order to minimize stress to the animals, a frame containing an infrared beam system was placed outside the cage.

\section{Grip Force Assessment}

The grip-strength test ${ }^{20}$ was used to determine rat skeletal muscle strength (GS). The grip-strength apparatus (Panlab-Harvard Apparatus, Spain) includes a pull bar attached to a dynamometer that acts as an isometric force transducer. The grip strength meter apparatus was placed horizontally, the animals being held by the tail and lowered towards the apparatus. Rats were permitted to grasp the bar being then pulled backward in the horizontal plane. Just before it lost grip, the force applied to the bar was measured as the peak tension. A minimum of three measurements per animal were taken, the results being averaged for analysis. The data are given as $\mathrm{g} / \mathrm{g}$ initial body weight.

\section{Statistical Analysis}

The means and the standard error of the mean (SEM) were calculated for each studied parameter. One-way ANOVA was used for statistical analysis of the results. Post-hoc pairwise comparisons Dunnett's test were used. (Tables 1 and 2). Statistical analysis of the results was done using the Student's $t$-test (Activity data in Table 3).

\section{Results}

As can be seen in Table 1, the presence of the tumour resulted in an important loss of body weight, -shown as decrement in weight increase- which is associated with anorexia. Indeed, the animals ate at least $30 \%$ less than the control non-tumourinoculated animals. This is linked with a significant decrease in the weight of the gastrointestinal tract.

Table 2 depicts the skeletal muscles and adipose tissue weights in both control and tumour-bearing rats. As can be seen, the tumour resulted in important decreases in the mass of all muscles studied including the heart. The significant decreases affected gastrocnemius (GSN) (15\%) (Figure 1), soleus $(8 \%)$, tibialis $(10 \%)$ and extensor digitorum longus (EDL) $(14 \%)$. These results reinforce the idea that muscle wasting is one of the main characteristics of cancer cachexia $^{5,21}$ and leads to decreased muscle performance and consequently quality of life. ${ }^{20}$ In the case of the heart, the decrease was $11 \%$ (Table 2); this decrease in heart weight also affects cardiac function, as we have previously described. ${ }^{22,23}$ Concerning adipose tissue, tumour burden also resulted in significant decreases that affected both white adipose (38\%) and brown adipose tissues (33\%). These results agree with previous studies performed using the same tumour model. ${ }^{23-25}$

$\beta 2$-agonist treatment (formoterol) resulted in a weight gain in GSN and tibialis muscles (Table 2). In spite of these positive effects, formoterol treatment did not affect tumour volume (Table 1). The effects of formoterol on muscle weight can also be seen in function. Indeed,

Table I Effects of Formoterol and Dantrolene Treatments on Food Intake, Body Weight and Tumour Content in Tumour-Bearing Rats

\begin{tabular}{|c|c|c|c|c|c|}
\hline \multirow[t]{2}{*}{ Parameters } & \multirow[t]{2}{*}{ C } & \multirow[t]{2}{*}{$\mathbf{T}$} & \multicolumn{3}{|c|}{ Experimental Groups } \\
\hline & & & TF & TD & TFD \\
\hline IBW & $206 \pm 5$ & $204 \pm 3$ & $206 \pm 3$ & $203 \pm 5$ & $206 \pm 3$ \\
\hline FBW & $249 \pm 6$ & $206 \pm 8 * * *$ & $211 \pm 4$ & $193 \pm 8$ & $213 \pm 4$ \\
\hline$\triangle \mathrm{BW}$ & $43 \pm 2$ & $2 \pm 6 * * * *$ & $5 \pm 1$ & $-10 \pm 4$ & $7 \pm 3$ \\
\hline Carcass & $82 \pm 5$ & $77 \pm 3$ & $79 \pm 2$ & $72 \pm 2$ & $77 \pm 2$ \\
\hline Food intake & $62 \pm 0.3$ & $43 \pm 4 * *$ & $45 \pm 4$ & $4 \mid \pm 4$ & $42 \pm 3$ \\
\hline GIT & $10.2 \pm 0.3$ & $6.0 \pm 0.5 * * * *$ & $5.8 \pm 0.4$ & $5.5 \pm 0.3$ & $5.9 \pm 0.2$ \\
\hline Tumour volume $(\mathrm{mL})$ & - & $58.4 \pm 6$ & $67 \pm 2.7$ & $69.5 \pm 4$ & $65 \pm 3.1$ \\
\hline
\end{tabular}

Notes: Results are mean \pm SEM for the number of animals: C: rats without tumour (6); T: tumour-bearing rats (6); TF: treated with formoterol (8); TD: treated with dantrolene (6); TFD: treated with both formoterol and dantrolene (8). IBW: initial body weight, FBW: final body weight (without tumour) and $\triangle B W$ (difference between IBW and FBW) are expressed as g. Food intake is expressed as g/I00g IBW and refers to the cumulative intake (7 days). GIT: Gastrointestinal tract and Carcass (body

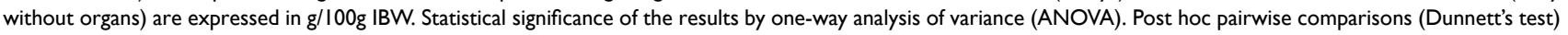
were performed. Values that are significantly different by the ANOVA test from the control group are indicated by $*^{*} \mathrm{p}<0.0 \mathrm{I}$, $*_{* *} \mathrm{p}<0.00 \mathrm{I}$, $* * * * \mathrm{p}<0.000 \mathrm{I}$; no differences are observed between the tumour non-treated and tumour treated animal groups. 
Table 2 Effects of Formoterol and Dantrolene Treatments on Muscle and Adipose Tissue Weight in Tumour-Bearing Rats

\begin{tabular}{|c|c|c|c|c|c|}
\hline \multirow[t]{2}{*}{ Parameters } & \multirow[t]{2}{*}{ C } & \multirow[t]{2}{*}{$\mathbf{T}$} & \multicolumn{3}{|c|}{ Experimental Groups } \\
\hline & & & TF & TD & TFD \\
\hline \multicolumn{6}{|l|}{ Muscle Weights } \\
\hline Soleus & $50 \pm 1$ & $46 \pm 2$ & $48 \pm 2$ & $42 \pm 2$ & $46 \pm 1$ \\
\hline Tibialis & $213 \pm 4$ & $191 \pm 9$ & $219 \pm 8^{\# \#}$ & $180 \pm 7$ & $210 \pm 6$ \\
\hline EDL & $51 \pm 1$ & $44 \pm 2$ & $50 \pm 2$ & $40 \pm 1$ & $48 \pm 1$ \\
\hline Heart & $367 \pm 9$ & $325 \pm 11$ & $315 \pm 9$ & $315 \pm 9$ & $329 \pm 8$ \\
\hline \multicolumn{6}{|l|}{ Adipose Weights } \\
\hline dWAT & $1050 \pm 151$ & $646 \pm 63 *$ & $442 \pm 55$ & $535 \pm 99(5)$ & $554 \pm 64$ \\
\hline BAT & $180 \pm 13$ & $101 \pm 6 * *$ & $103 \pm 5$ & $97 \pm 9$ & $119 \pm 6$ \\
\hline
\end{tabular}

Notes: Results are mean \pm SEM for the number of animals: C: rats without tumour (6); T: tumour-bearing rats (6); TF: treated with formoterol (8); TD: treated with dantrolene (6); TFD: treated with both formoterol and dantrolene (8). All weights are normalized by initial body weight (IBW) and are expressed in mg/I00g IBW. EDL: extensor digitorum longus. IWAT: dorsal white adipose tissue; BAT: brown adipose tissue. Statistical significance of the results by one-way analysis of variance (ANOVA). Post hoc pairwise comparisons (Dunnett's test) were performed, except for BAT which post hoc Kruskal-Wallis test is performed. Values that are significantly different by the ANOVA test from the control group are indicated by ${ }^{*} \mathrm{p}<0.05$, ${ }^{*} \mathrm{p}<0.01$; from the tumour non-treated animal group are indicated by ${ }^{\#} \mathrm{p}<0.0 \mathrm{I}$.

Table 3 Last 24 Hours of Physical Activity in Rats Bearing the Yoshida AH-I30 Ascites Hepatoma Treated with Formoterol and Dantrolene

\begin{tabular}{|c|c|c|c|c|c|}
\hline \multirow[t]{2}{*}{ Parameters } & \multirow[t]{2}{*}{ C } & \multirow[t]{2}{*}{$\mathbf{T}$} & \multicolumn{3}{|c|}{ Experimental Groups } \\
\hline & & & TF & TD & TFD \\
\hline $\begin{array}{l}\text { Total physical activity } \\
\text { Stereotyped movements } \\
\text { Locomotor movements }\end{array}$ & $\begin{array}{l}39468 \pm 5294 \\
5074 \pm 766 \\
34394 \pm 4620\end{array}$ & $\begin{array}{l}18886 \pm 5182 * \\
2216 \pm 477 * \\
1667 \mid \pm 4819 *\end{array}$ & $\begin{array}{l}31134 \pm 1337^{\#} \\
5678 \pm 676^{\# \#} \\
25455 \pm 1128^{\#}\end{array}$ & $\begin{array}{l}23654 \pm 187 \mid \\
3912 \pm 653 \\
19742 \pm 2485\end{array}$ & $\begin{array}{l}34074 \pm 435 \\
3315 \pm 256 \\
30759 \pm 179\end{array}$ \\
\hline $\begin{array}{l}\text { Maximum speed } \\
\text { Total travelled distance }\end{array}$ & $\begin{array}{l}37 \pm 6 \\
307 \mid I \pm 6181\end{array}$ & $\begin{array}{l}26 \pm 6 \\
16729 \pm 4374\end{array}$ & $\begin{array}{l}50 \pm 4^{\# \#} \\
41276 \pm 6448\end{array}$ & $\begin{array}{l}52 \pm 4^{\#} \\
32592 \pm 274 I^{\#}\end{array}$ & $\begin{array}{l}57 \pm 6^{\#} \\
37793 \pm 357\end{array}$ \\
\hline
\end{tabular}

Notes: Results are mean \pm S.E.M. for the number of animals: C: rats without tumour (4); T: tumour-bearing rats (4); TF: treated with formoterol (8); TD: treated with dantrolene (4); TFD: treated with both formoterol and dantrolene (2). Physical activity is expressed in activity units. Stereotyped movements include movements without shifting (eating and cleaning movements); conversely, locomotor movements include movements with shifting. Maximum speed is expressed in $\mathrm{cm} / \mathrm{s}$. Travelled distance is expressed in $\mathrm{cm}$. Values that are significantly different by the Student's $t$-test from the control group are indicated by *p $<0.05$ and from the tumour non-treated animal group are indicated by ${ }^{\#} \mathrm{P}<0.05,{ }^{\#} \mathrm{p}<0.01$.

formoterol positively counteracts the decreased grip force induced by the tumour (Figure 2). Interestingly, it also had a beneficial effect on physical activity (Table 3).

The results clearly showed that the use of dantrolene alone had no beneficial effects on food intake, body weight (Table 1), or any of the muscle and adipose tissue weights studied (Table 2). Performance parameters (grip force and physical activity) were also not affected by dantrolene treatment (Figure 2 and Table 3 ) with the only exception of an increase in the maximum speed and total travelled distance. In fact, a higher dose of dantrolene was not able to decrease protein degradation rates in rats bearing the AH-130 hepatoma. ${ }^{17}$

\section{Discussion}

The experimental model used in this study, the Yoshida AH130 ascites hepatoma, represents a very fast growing tumour which leads to very marked cachexia involving muscle and fat wasting. ${ }^{26}$ An exhaustive characterization of the model has been undertaken by our research team. ${ }^{20,27,28}$

Dantrolene is an inhibitor of the RyR1 which inhibits intracellular calcium release from the SR. ${ }^{29}$ Ryanodine receptor is a protein that allows for calcium ions to be exported from the sarcoplasmic reticulum into the cytoplasm leading to contraction. In normal conditions, calcium is returned into the SR against a concentration gradient through the action of the sarcoendoplasmic reticulum $\mathrm{Ca}^{2+}$-ATPase (SERCA) pumps. ${ }^{30}$ However, modification of RyR1 protein, such as oxidation, can occur during cancer cachexia. ${ }^{15}$ This results in calcium leakage associated with defective mitochondrial function and an increase in calcium-dependent proteolysis, which is mediated by the calcium-dependent proteases, also known as calpains. ${ }^{31}$ Bearing this in mind, the objective 


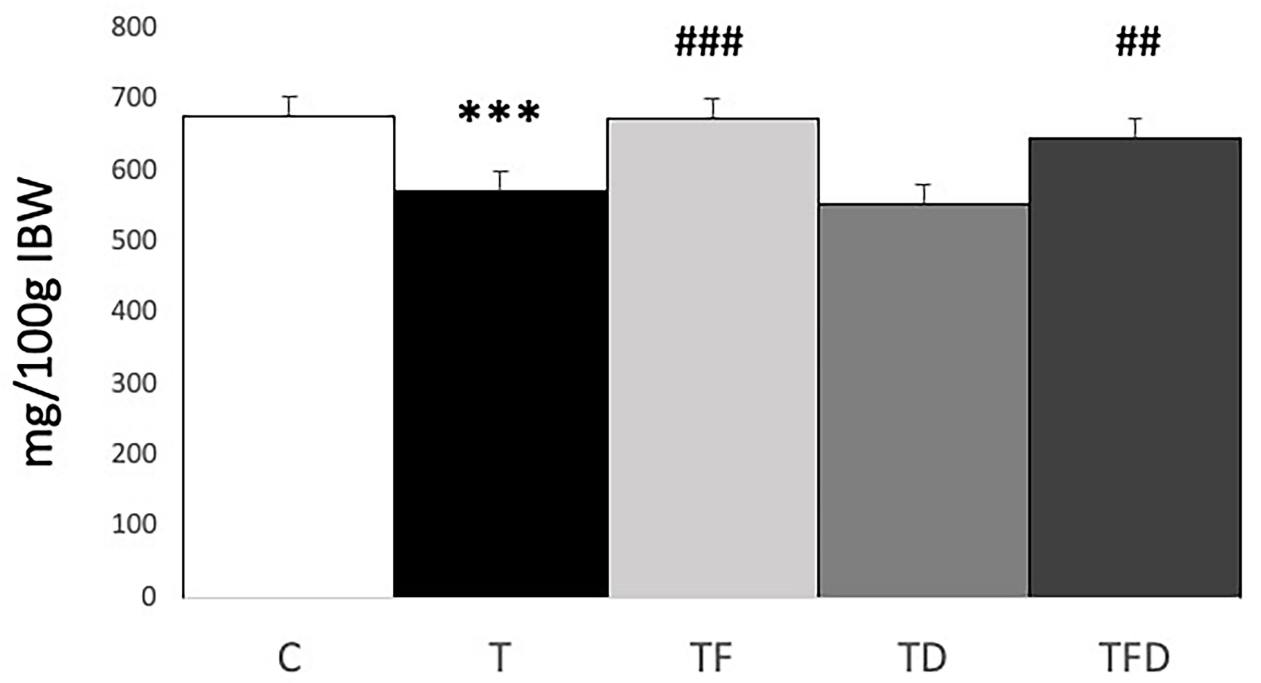

Figure I Gastrocnemius weight in tumour-bearing rats. Results are mean \pm SEM for the number of animals: C: rats without tumour (6); T: tumour-bearing rats (6); TF: treated with formoterol (8); TD: treated with dantrolene (6); TFD: treated with both formoterol and dantrolene (8). All weights are normalized by initial body weight (IBW)

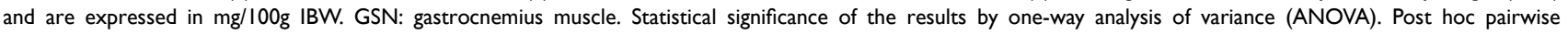
comparisons (Dunnett's test) were performed. Values that are significantly different by the ANOVA test from the control group are indicated by $* * * p<0.00 \mathrm{I}$; from the tumour non-treated animal group are indicated by ${ }^{\#} \mathrm{p}<0.01, \ldots \ldots+0.001$.

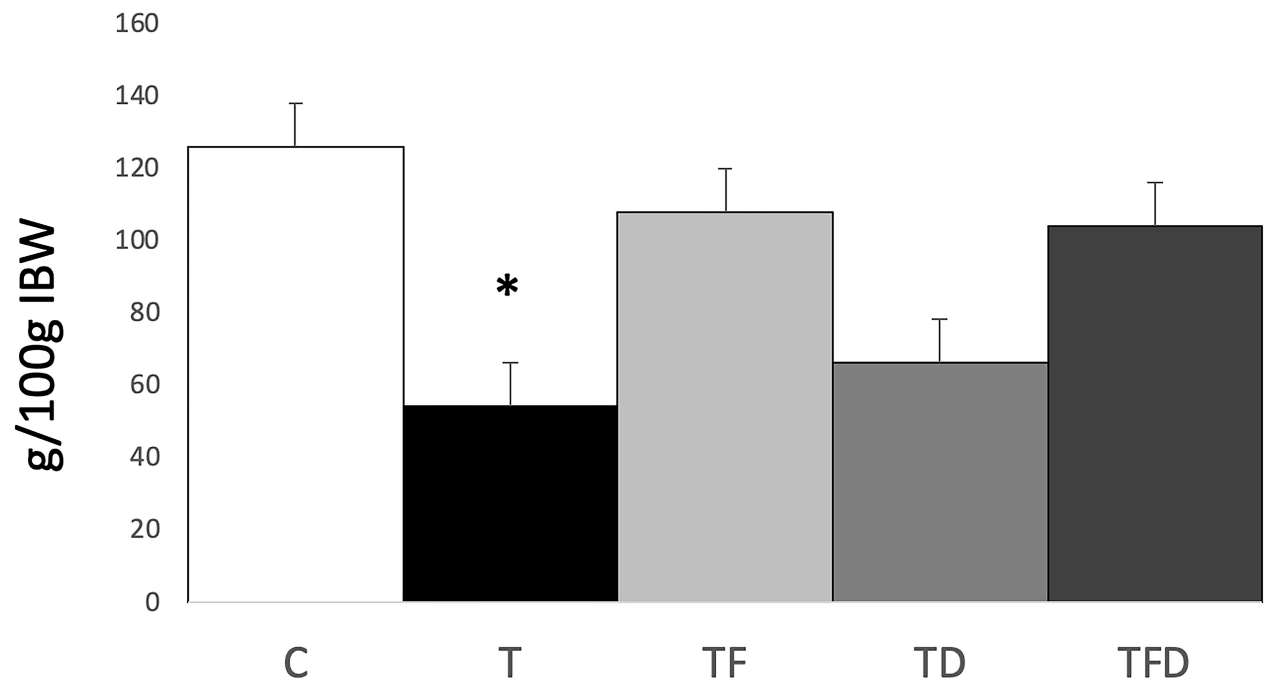

Figure 2 Grip force increase in tumour-bearing rats. Grip force increase is the difference between final versus initial force expressed in g/I00g IBW. Statistical significance of the results by one-way analysis of variance (ANOVA). Post hoc pairwise comparisons (Dunnett's test) were performed. Values that are significantly different by the ANOVA test from the control group are indicated by ${ }^{*} \mathrm{p}<0.05$; no differences are observed between the tumour non-treated and tumour treated animal groups.

of the present investigation was to block the outflow of calcium by the use of dantrolene, either alone or in a combination with formoterol. In a previous investigation, Pin et $\mathrm{al}^{17}$ used dantrolene in tumour-bearing rats as a an anti-proteolytic strategy to inhibit the calpain system which is activated in skeletal muscle during cancer cachexia. $^{31}$ Their observations suggest that the inhibition of just an individual proteolytic system is not sufficient to counteract tumour-caused muscle wasting. Bearing this in mind, we tested the combination of formoterol and dantrolene in order to test a possible additive effect on muscle wasting. No signs of toxicity were detected at the dose used $(5 \mathrm{mg} / \mathrm{kg}$ ). We used this dose because of previous results obtained with the drug in experiments related to inflammatory conditions (unpublished data). The rationale was that, since formoterol decreases protein degradation in skeletal muscle in cancer and dantrolene acts on a completely different mechanism, by decreasing calcium overload at the level of the sarcoplasmic reticulum, there could be could additive effects of the combination. Indeed, 
sarcoplasmic alterations involving calcium overload have been described in cancer cachexia. ${ }^{32}$ Unfortunately, dantrolene did not have any additive effects on the beneficial effect of formoterol on muscle wasting. However, dantrolene treatment alone resulted in an improvement in physical activity- speed and total travelled distance. Further investigations are needed to clarify this effect.

\section{Conclusions}

In view of all the results, it is, therefore, concluded that: a) calcium blockage does not seem to be a valid approach for treating muscle wasting, and $b$ ) that no synergy seems to exist between $\beta 2$-agonist treatment and the use of the calcium outflow blocker.

\section{Abbreviations}

EDL, extensor digitorum longus; GSN, gastrocnemius muscle; RyR1, ryanodine receptor 1; s.c., subcutaneous administration; SERCA, sarcoendoplasmic reticulum $\mathrm{Ca}^{2+}$-ATPase; SR, sarcoplasmic reticulum; TB, tumour bearers; TD, animals treated with dantrolene; TF, animals treated with Formoterol; TFD, double-treated animals; TPA, total physical activity.

\section{Data Sharing Statement}

All data generated or analysed during this study are included in this published article.

\section{Ethics Approval and Consent to Participate}

All animal manipulations were made in accordance with the European Community guidelines for the use of laboratory animals. They were cared for in compliance with the Policy on Humane Care and Use of Laboratory Animals (ILAR 2011) and in accordance with the ethical standards laid down in the 1964 Declaration of Helsinki and its later amendments. In addition, Ethics approval was granted by the Ethics Committee of the University of Barcelona and the Generalitat de Catalunya.

\section{Consent to publish}

All authors involved in the present investigation have read, approved the final form of the manuscript and have given consent to publish.

\section{Acknowledgments}

This paper was presented at the 12th Cachexia Conference (Berlin) as a poster presentation with interim findings. The poster's abstract was published in J Cachexia Sarcopenia Muscle. 2020 Feb; 11(1): 286-329 (doi: 10.1002/ jesm.12551).

\section{Author Contributions}

All authors made a significant contribution to the work reported, whether that is in the conception, study design, execution, acquisition of data, analysis and interpretation, or in all these areas; took part in drafting, revising or critically reviewing the article; gave final approval of the version to be published; have agreed on the journal to which the article has been submitted; and agree to be accountable for all aspects of the work.

\section{Funding}

This work was supported by a grant from the Ministerio de Economia y Competitividad (SAF2015-65589-P), this funding supported the design of the study, analysis and interpretation of data.

\section{Disclosure}

The authors report no conflicts of interest related to employment, consultancies, stock ownership, honoraria, paid expert testimony, patent applications/registrations, and grants or other funding.

\section{References}

1. Loberg RD, Bradley DA, Tomlins SA, Chinnaiyan AM, Pienta KJ. The lethal phenotype of cancer: the molecular basis of death due to malignancy. CA Cancer J Clin. 2007;57:225-241. doi:10.3322/ canjclin.57.4.225

2. Moses AWG, Slater C, Preston T, Barber MD, Fearon KCH. Reduced total energy expenditure and physical activity in cachectic patients with pancreatic cancer can be modulated by an energy and protein dense oral supplement enriched with n-3 fatty acids. $\mathrm{Br} J$ Cancer. 2004;90:996-1002. doi:10.1038/sj.bjc.6601620

3. Dewys WD, Begg C, Lavin PT, et al. Prognostic effect of weight loss prior to chemotherapy in cancer patients Eastern cooperative oncology group. Am J Med. 1980;69:491-497.

4. Muscaritoli M, Anker SD, Argiles J, et al. Consensus definition of sarcopenia, cachexia and pre-cachexia: joint document elaborated by Special Interest Groups (SIG) 'cachexia-anorexia in chronic wasting diseases' and 'nutrition in geriatrics'. Clin Nutr. 2010;29:154-159. doi:10.1016/j.clnu.2009.12.004

5. Evans WJ, Morley JE, Argilés J, et al. Cachexia: a new definition. Clin Nutr. 2008;27:793-799. doi:10.1016/j.clnu.2008. 06.013

6. Wolfe RR. The underappreciated role of muscle in health and disease. Am J Clin Nutr. 2006;84:475-482. doi:10.1093/ajen/84.3.475

7. Macciò A, Madeddu C, Gramignano G, et al. A randomized Phase III clinical trial of a combined treatment for cachexia in patients with gynecological cancers: evaluating the impact on metabolic and inflammatory profiles and quality of life. Gynecol Oncol. 2012;124:417-425. doi:10.1016/j.ygyno.2011.12.435 
8. Rogers ES, MacLeod RD, Stewart J, Bird SP, Keogh JWL. A randomised feasibility study of EPA and Cox-2 inhibitor (Celebrex) versus EPA, Cox-2 inhibitor (Celebrex), resistance training followed by ingestion of essential amino acids high in leucine in NSCLC cachectic patients-ACCeRT study. BMC Cancer. 2011;11:493. doi:10.1186/1471-2407-11-493

9. Busquets S, Figueras MT, Fuster G, et al. Anticachectic effects of formoterol: a drug for potential treatment of muscle wasting. Cancer Res. 2004;64:6725-6731. doi:10.1158/0008-5472.CAN-04-0425

10. Harcourt LJ, Schertzer JD, Ryall JG, Lynch GS. Low dose formoterol administration improves muscle function in dystrophic $\mathrm{mdx}$ mice without increasing fatigue. Neuromuscul Disord. 2007;17:47-55. doi:10.1016/j.nmd.2006.08.012

11. Busquets S, Toledo M, Sirisi S, et al. Formoterol and cancer muscle wasting in rats: effects on muscle force and total physical activity. Exp Ther Med. 2011;2:731-735. doi:10.3892/etm.2011.260

12. Greig CA, Johns N, Gray C, et al. Phase I/II trial of formoterol fumarate combined with megestrol acetate in cachectic patients with advanced malignancy. Support Care Cancer. 2014;22 1269-1275. doi:10.1007/s00520-013-2081-3

13. Dirksen RT. Sarcoplasmic reticulum-mitochondrial through-space coupling in skeletal muscle. Appl Physiol Nutr Metab. 2009;34: 389-395. doi:10.1139/H09-044

14. Rossi AE, Boncompagni S, Dirksen RT. Sarcoplasmic reticulum-mitochondrial symbiosis: bidirectional signaling in skeletal muscle. Exerc Sport Sci Rev. 2009;37:29-35. doi:10.1097/JES.0b0 $13 \mathrm{e} 3181911 \mathrm{fa} 4$

15. Waning DL, Mohammad KS, Reiken S, et al. Excess TGF- $\beta$ mediates muscle weakness associated with bone metastases in mice. Nat Med. 2015;21:1262-1271. doi:10.1038/nm.3961

16. Fischer DR, Sun X, Williams AB, et al. Dantrolene reduces serum TNFalpha and corticosterone levels and muscle calcium, calpain gene expression, and protein breakdown in septic rats. Shock. 2001; 15:200-207. doi:10.1097/00024382-200115030-00007

17. Pin F, Minero VG, Penna F, et al. Interference with $\mathrm{Ca} 2+$-dependent proteolysis does not alter the course of muscle wasting in experimental cancer cachexia. Front Physiol. 2017;8:213. doi:10.3389/ fphys.2017.00213

18. Busquets S, Serpe R, Toledo $M$, et al. 1-Carnitine: an adequate supplement for a multi-targeted anti-wasting therapy in cancer. Clin Nutr. 2012;31:889-895. doi:10.1016/j.clnu.2012.03.005

19. Directive $2010 / 63 / \mathrm{Eu}$ of the European parliament and of the council of 22 September 2010 on the protection of animals used for scientific purposes. Available from: http://data.europa.eu/eli/dir/2010/63/oj. Accessed February 18, 2021.
20. Toledo M, Busquets S, Sirisi S, et al. Cancer cachexia: physical activity and muscle force in tumour-bearing rats. Oncol Rep. 2011;25:189-193.

21. Fearon K, Strasser F, Anker SD, et al. Definition and classification of cancer cachexia: an international consensus. Lancet Oncol. 2011;12:489-495. doi:10.1016/S1470-2045(10)70218-7

22. Toledo M, Springer J, Busquets S, et al. Formoterol in the treatment of experimental cancer cachexia: effects on heart function. J Cachexia Sarcopenia Muscle. 2014;5(4):315-320. doi:10.1007/ s13539-014-0153-y

23. Olivan M, Springer J, Busquets S, et al. Theophylline is able to partially revert cachexia in tumour-bearing rats. Nutr Metab. 2012;9:76. doi:10.1186/1743-7075-9-76

24. Carbó N, López-Soriano J, Costelli P, et al. Interleukin-15 antagonizes muscle protein waste in tumour-bearing rats. $\mathrm{Br} J$ Cancer. 2000;83:526-531. doi:10.1054/bjoc.2000.1299

25. Busquets S, Serpe R, Sirisi S, et al. Megestrol acetate: its impact on muscle protein metabolism supports its use in cancer cachexia. Clin Nutr. 2010;29:733-737. doi:10.1016/j.clnu.2010.06.003

26. Tessitore L, Costelli P, Bonetti G, Baccino FM. Cancer cachexia, malnutrition, and tissue protein turnover in experimental animals. Arch Biochem Biophys. 1993;306:52-58. doi:10.1006/abbi.1993.1479

27. Llovera M, Garcia-Martinez C, Agell N, Lopez-Soriano FJ, Argiles JM. Muscle wasting associated with cancer cachexia is linked to an important activation of the ATP-dependent ubiquitin-mediated proteolysis. Int J Cancer. 1995;61:138-141. doi:10.1002/ijc.29106 10123

28. García-Martínez C, Llovera M, Agell N, López-Soriano FJ, Argilés JM. Ubiquitin gene expression in skeletal muscle is increased by tumour necrosis factor-alpha. Biochem Biophys Res Commun. 1994;201:682-686. doi:10.1006/bbrc.1994.1754

29. Muehlschlegel S, Sims JR. Dantrolene: mechanisms of neuroprotection and possible clinical applications in the neurointensive care unit. Neurocrit Care. 2009;10:103-115. doi:10.1007/s12028-008-9133-4

30. Zalk R, Lehnart SE, Marks AR. Modulation of the ryanodine receptor and intracellular calcium. Annu Rev Biochem. 2007;76:367-385. doi:10.1146/annurev.biochem.76.053105.094237

31. Costelli P, Reffo P, Penna F, Autelli R, Bonelli G, Baccino FM. Ca(2 + )-dependent proteolysis in muscle wasting. Int J Biochem Cell Biol. 2005;37:2134-2146. doi:10.1016/j.biocel.2005.03.010

32. Fontes-Oliveira CC, Busquets S, Toledo M, et al. Mitochondrial and sarcoplasmic reticulum abnormalities in cancer cachexia: altered energetic efficiency? Biochim Biophys Acta. 2013;1830:2770-2778. doi:10.1016/j.bbagen.2012.11.009
OncoTargets and Therapy

\section{Publish your work in this journal}

OncoTargets and Therapy is an international, peer-reviewed, open access journal focusing on the pathological basis of all cancers, potential targets for therapy and treatment protocols employed to improve the management of cancer patients. The journal also focuses on the impact of management programs and new therapeutic

Submit your manuscript here: https://www.dovepress.com/oncotargets-and-therapy-journa agents and protocols on patient perspectives such as quality of life, adherence and satisfaction. The manuscript management system is completely online and includes a very quick and fair peer-review system, which is all easy to use. Visit http://www.dovepress.com/ testimonials.php to read real quotes from published authors. 